\title{
Prevalência de casos de doenças autoimunes e imunodeficiências primárias registradas em hospitais no Agreste de Pernambuco
}

Prevalence of cases of autoimmune diseases and primary immunodeficiencies registered in hospitals in Agreste de Pernambuco

Prevalencia de casos de enfermedades autoinmunes e inmunodeficiencias primarias registrados en hospitales de Agreste de Pernambuco

\section{Resumo}

Michael Gabriel Agustinho Barbosa

ORCID: https://orcid.org/0000-0002-6553-3962 Centro Universitário do Vale do Ipojuca, Brasil E-mail: michaelgabrielscc1210@hotmail.com Patrícia Alves Genuino ORCID: https://orcid.org/0000-0001-5571-2839 Faculdade Boa Viagem, Brasil E-mail: patuxa_22@hotmail.com

Emanuela Ingridy Silva ORCID: https://orcid.org/0000-0001-7908-0303 Faculdade Mauricio de Nassau, Brasil E-mail: emanuela9530@gmail.com

Simone Martins Dos Santos ORCID: https://orcid.org/0000-0002-3303-0869 Centro Universitário do Vale do Ipojuca, Brasil E-mail: symone-saopaulo@hotmail.com Severina Ridrigues De Oliveira Lins ORCID: https://orcid.org/0000-0002-7641-7158 Centro Universitário do Vale do Ipojuca, Brasil As doenças autoimunes são patológias onde o próprio organismo desenvolve uma resposta imune contra um autoantígeno (autológo). Existem vários fatores que desencadeiam essa perca de tolerância ao próprio organismo, como por exemplo, os genéticos. O risco hereditário para a maioria dessas patológicas é atribuível a múltiplos loci, cuja maior contribuição é feita pelos os genes do MHC. Objetivou-se, com esta pesquisa, fazer levantamento de casos diagnosticados de Doenças Autoimunes (DAIs) e Imunodeficiências Primaria (IP) em cidades localizadas no Agreste e na capital de Pernambuco. No Agreste, foram selecionadas quatro cidades para o desenvolvimento desse trabalho. Após a liberação da carta de anuência, e aprovação do comitê de ética e pesquisa (CEP UNIFAVIP), iniciou a pesquisa. Foram analisados 1 mil prontuários, de pacientes diagnosticados com estas patologias, entre os anos de 2016 a 2018. Desses, apenas 94 prontuários foram utilizados por conterem informações completas para os resultados deste trabalho. Foram identificados 93 registros de DAIs e 1 de IDP. Mesmo não tendo sido um dos objetivos propostos, inicialmente pela pesquisa, foram constatadas inúmeras dificuldades tanto no acesso quanto na interpretação dos prontuários, como por exemplo dados incompletos e SID da doença diagnosticada. A doença celíaca foi a patologia que apresentou maior prevalência no agreste pernambucano.

Palavras-chave: Autoantigeno; Levantamento; Prontuário.

\begin{abstract}
Autoimmune diseases are pathologies where the body itself develops an immune response against an autoantigen (autologous). There are several factors that trigger this loss of tolerance to the organism itself, such as genetic factors. The hereditary risk for most of these pathologies is attributable to multiple loci, the major contribution of which is made by the MHC genes. The objective of this research was to survey diagnosed cases of Autoimmune Diseases (DAIs) and Primary Immunodeficiencies (IP) in cities located in Agreste and in the capital of Pernambuco. In Agreste, four cities were selected for the development of this work. After the approval letter was released, and the ethics and research committee (CEP UNIFAVIP) approved, the research began. 1,000 medical records of patients diagnosed with these pathologies were analyzed between the years 2016 to 2018. Of these, only 94 medical records were used because they contain complete information for the results of this work. 93 records of DAIs and 1 IDP were identified. Even though it was not one of the objectives proposed, initially by the research, numerous difficulties were found both in access and in
\end{abstract}


the interpretation of medical records, such as incomplete data and SID of the diagnosed disease. Celiac disease was the pathology that had the highest prevalence in the harsh Pernambuco.

Keywords: Autoantigen; Survey; Medical record.

\section{Resumen}

Las enfermedades autoinmunes son patologías en las que el propio organismo desarrolla una respuesta inmunitaria frente a un autoantígeno (autólogo). Son varios los factores que desencadenan esta pérdida de tolerancia al propio organismo, como los factores genéticos. El riesgo hereditario de la mayoría de estas patologías es atribuible a múltiples loci, cuya principal contribución la realizan los genes MHC. El objetivo de esta investigación fue relevar casos diagnosticados de Enfermedades Autoinmunes (IAD) e Inmunodeficiencias Primarias (PI) en ciudades ubicadas en Agreste y en la capital de Pernambuco. En Agreste se seleccionaron cuatro ciudades para el desarrollo de este trabajo. Después de que se publicó la carta de aprobación y el comité de ética e investigación (CEP UNIFAVIP) la aprobó, comenzó la investigación. Se analizaron 1,000 historias clínicas de pacientes diagnosticados con estas patologías entre los años 2016 a 2018. De estas, solo se utilizaron 94 historias clínicas porque contienen información completa para los resultados de este trabajo. Se identificaron 93 registros de DAI y 1 PDI. Si bien no era uno de los objetivos propuestos, inicialmente por la investigación, se encontraron numerosas dificultades tanto en el acceso como en la interpretación de las historias clínicas, como datos incompletos y DIM de la enfermedad diagnosticada. La enfermedad celíaca fue la patología de mayor prevalencia en el agreste Pernambuco.

Palabras chave: Autoantígeno; Encuesta; Historial médico.

\section{Introdução}

Doença autoimune (DAI) é caracterizada quando o organismo deixa de reconhecer o self do no self (o próprio do não próprio). Estas patologias resultam, frequentemente, em lesões recorrentes de vários tecidos e órgãos (Barbosa et al., 2019).

As doenças autoimunes são caracterizadas por multifatores etiopatogênicos, que se associam com outros como por exemplo o ambiental, tudo a que o indivíduo está exposto no dia a dia e que quando não se tem anticorpos contra alguns microrganismos, irá resultar em uma patologia. Outro fator frequentemente associado é o genético, quando se tem a transmissão na transcrição de genes regulatórios de fatores imunológicos. Com relação a esses últimos, o aumento da síntese de imunoglobulinas G, M e A ( $\operatorname{IgG}$, IgM e IgA), reações de hipersensibilidade do tipo II e III, e distúrbios da tolerância central e periférica, o aumento da expressão de antígeno leucocitário humano (HLA) e a associação do desequilíbrio da resposta imunológica, são que merecem maior atenção (Barbosa et al.,2019).

As imunodeficiências resultam na incapacidade do sistema imunológico de realizar seu papel fisiológico, que é neutralizar células estranhas ou anormais que atacam o organismo, como por exemplo, os vírus, bactérias, fungos e até células tumorais. Os quadros de imunodeficiências consistem em infecções atípicas por bactérias, vírus, entre outros organismos capazes de desenvolver uma resposta imunológica (Picard et al., 2015).

Indivíduos que apresentam alguma imunodeficiência, 25\% deles também apresentam algum tipo de DAI, a literatura descreve que esses dois grupos de doenças sempre estão associadas uma com a outra (Errante et al., 2016).

As imunodeficiências primárias são causadas por uma deficiência do receptor interleucina 12 o que deixa o indivíduo mais predisposto a infecções por fungos, bactérias e micobacteriose atípica. A IL-12 é uma citocina secretada pelos linfócitos B, neutrófilos, células dendríticas e macrófagos, após a ativação por células apresentadoras de antígenos (Rost., 2017).

Algumas doenças autoimunes são desencadeadas através do uso abusivo de medicamentos, como por exemplo, lúpus, mal de Alzheimer entre outros medicamentos que são utilizados para o tratamento de alguma doença e quando se tem o uso abusivo ou quando se tem uma longa duração do tratamento dessas doenças, esses medicamentos podem desencadear doenças autoimunes (Carvalho et al.,2016).

Segundo Tolentino, (2017), no Brasil, tanto em âmbito nacional ou regional, existe uma escasseeis em dados epidemiológicos oficiais referentes à incidência e à prevalência de doenças autoimunes. Isso se dá, devido à inexistência de 
política específica de atenção a esse grupo de doença, haja vista que essas doenças não são de notificação compulsória. Dentre o vasto número de morbidade que compõem esse grupo existente no país.

À luz deste contexto e sabendo-se da falta de registro científico sabre dados concretos sobre esses grupos de doenças no estado de Pernambuco, destacando-se o interior do estado, percebeu-se a necessidade de uma análise retrospectiva dos resultados documentados acerca desses grupos de patologias.

\section{Metodologia}

Tratou-se de um estudo descritivo, transversal e procedimento técnico do tipo documental, com abordagem quantitativa. A pesquisa foi realizada em quatro municípios da Agreste pernambucano e em unidades de Saúde, localizada na capital do Estado. A pesquisa foi aprovada pelo Comitê de Ética e Pesquisa UNIFAVIP (CAAE: 00580818.0.0000.5666). Após o término da pesquisa, totalizaram-se $(\mathrm{N}=94)$ prontuários analisados, os quais foram considerados para a compilação dos resultados deste trabalho.

Os dados foram coletados diretamente de prontuários disponibilizados pelos responsáveis diretos de cada uma das unidades de saúde, previamente contactadas e que emitiram a carta de anuência. A investigação dos dados foi realizada em dias e horários pré-estabelecidos pela a direção de cada Unidade de saúde e em sala reservada, após a aprovação do Termo de Compromisso de Utilização de Dados (TCUD).

Como critérios de inclusão consideraram-se: data de nascimento, sexo, sintomas, sinais, exames realizados, diagnóstico e tratamento. Foram excluídos os prontuários que não tinham um diagnóstico conclusivo para qualquer desses grupos de doenças como demonstrado no esquema (Figura 1).

Figura 1: Esquema dos prontuários validos e doenças auto imunes e imunodeficiências primarias documentadas no agreste pernambucano, entre 2016-2019.

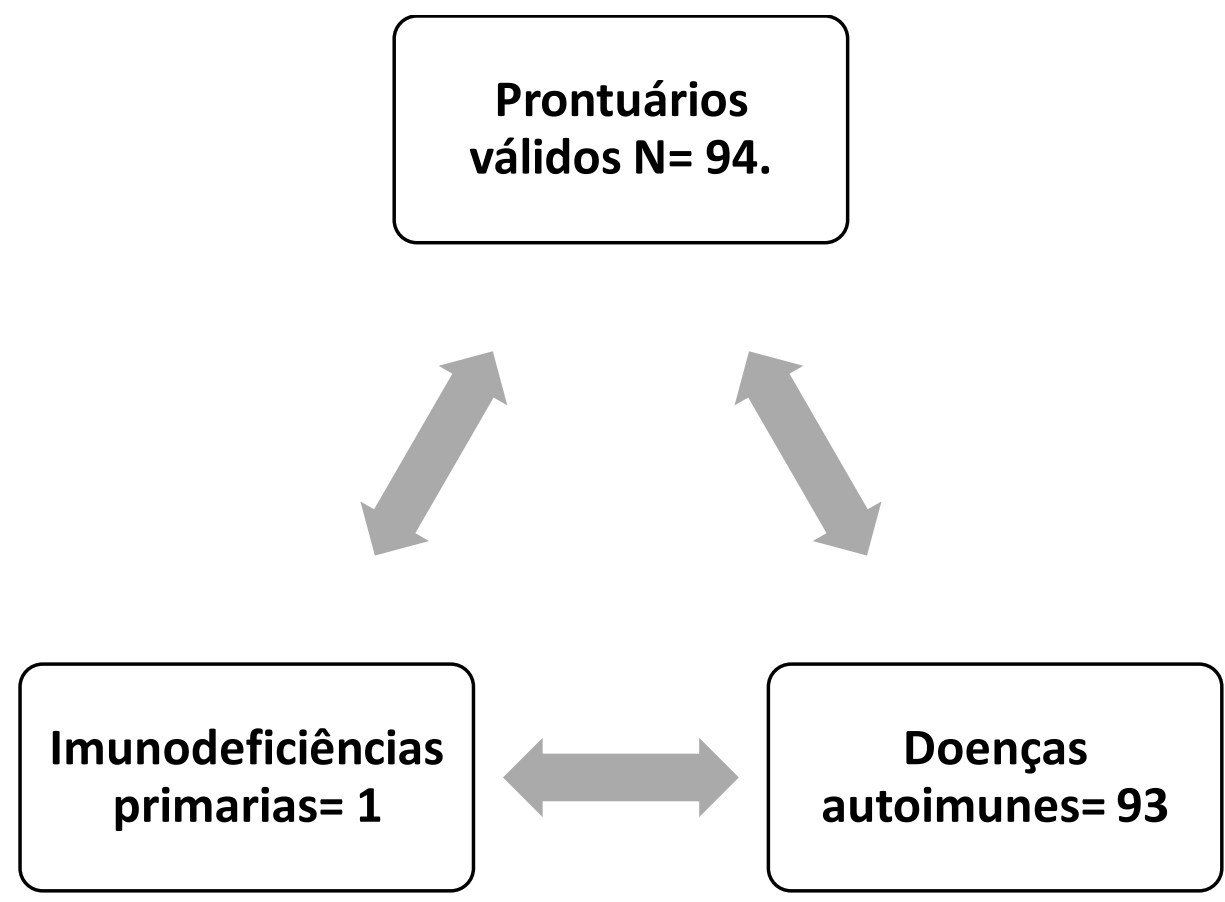

Fonte: Autores. 


\section{Resultados e Discussão}

Os dados da atual pesquisa relatam que entre os anos de 2016 a 2018 foram diagnosticados 19 tipos de doenças autoimunes e/ou imunodeficiência primaria, em todo o estado de Pernambuco, totalizando assim 93 casos de Doenças autoimunes e 1 caso de imunodeficiência primaria. A doença que apresentou maior prevalência foi a doença celíaca com aproximadamente $21,27 \%$ de todos os casos de DAIs. Em seguida foi Espondilite anquilosante representando 19,15\%, e Alopecia aerata representou $10 \%$ dos casos das DAIs diagnosticadas em Pernambuco.

A cidade que houve uma maior incidência foi o Recife, com $49 \%$ de casos de DAIs diagnosticadas, com incidência de casos de Alopecia aerata com 10 casos, quando comparado com as demais cidades a maior prevalência de casos de DAIs foi a doença celíaca. Quando se faz uma análise dos casos registrados, é possível notar que a população feminina com 51,06\% dos casos de DAIs, enquanto a população masculina com 23,40\%. Em um estudo realizado por Costa (2019), chegou à conclusão de que em média 3\% dos habitantes de todo o mundo são portadores de doenças autoimunes, em indivíduos do sexo feminino tem maior ocorrência que o sexo masculino e em geral o diagnóstico dessas doenças ocorrem após uma sequência de sintomas ou até mesmo com uma única crise dependendo de qual doença autoimune o indivíduo é portador (Costa,2019).

Outros estudos acompanham a média de resultados, onde em uma pesquisa realizada no ano de 2016 no estado de Minas Gerais foram registrados 407 casos de portadores autoimunes de 24 tipos com prevalência maior no sexo feminino. Em outro estudo em Brasília realizado no ano de 2017 foram diagnosticados 145 pacientes com algum tipo de DAIs em acompanhamento no hospital universitário do estado, com uma prevalência maior no sexo feminino (Tolentino Júnior,2017 \& Lopes,2018).

Na tabela 1 estão descritas as doenças diagnósticas entre o ano de 2016 a 2018 em cidades localizadas no agreste foram elas: Toritama, Taquaritinga do Norte, Garanhuns, Limoeiro, e em Recife no ano de 2019. Na tabela 2 está descrito por cada município os registros de doenças autoimunes e imunodeficiências primarias. 
Tabela 1: Diagnósticos de doenças autoimunes e de imunodeficiências primárias, notificados no Agreste de Pernambuco, entre 2016 e 2018.

\begin{tabular}{|l|l|}
\hline Doença & Total \\
\hline Anemia hemolítica & 1 \\
\hline Doença celíaca & 20 \\
\hline Espondilite anquilosante & 18 \\
\hline Miosite & 2 \\
\hline Lupus eritematoso sistêmico & 3 \\
\hline Purpura & 2 \\
\hline Febre reumática & 1 \\
\hline Artrite reumatoide & 3 \\
\hline Esclerose múltipla & 2 \\
\hline Oftalmopatia de graves & 1 \\
\hline Alopecia aerata & 10 \\
\hline Diabetes tipo 1 & 7 \\
\hline Doença de Graves & 4 \\
\hline Líquen plano & 2 \\
\hline Pênfigo foliáceo & 2 \\
\hline Psoríase & 5 \\
\hline Tireoidite de Hashimoto & 5 \\
\hline Vitiligo & 6 \\
\hline Total & 18 Doenças \\
\hline
\end{tabular}

Fonte: Autores. 
Research, Society and Development, v. 10, n. 2, e50410212681, 2021

(CC BY 4.0) | ISSN 2525-3409 | DOI: http://dx.doi.org/10.33448/rsd-v10i2.12681

Tabela 2: Diagnósticos de doenças autoimunes e de imunodeficiências primárias, notificados no Agreste de Pernambuco, por município, entre 2016 e 2018.

Casos de doenças autoimunes (DAI), notificados em Limoeiro, entre 2016 e 2018.

O Hospital Regional de Limoeiro registrou 11 ocorrências de DAIs, ao longo do triênio 2016 a 2018. Houve prevalência da doença celíaca, com 7 registros. O predomínio dos casos foi em pacientes do sexo feminino.

\begin{tabular}{|c|c|c|c|}
\hline Doença celíaca & & \multicolumn{2}{|c|}{7} \\
\hline Artrite reumatoide & & \multicolumn{2}{|c|}{1} \\
\hline Esclerose múltipla & & \multicolumn{2}{|c|}{2} \\
\hline Purpura & & \multicolumn{2}{|c|}{1} \\
\hline \multicolumn{4}{|c|}{ Diagnósticos de DAIs e de imunodeficiência primaria, por sexo e ano de diagnóstico. } \\
\hline Doença & Sexo masculino & Sexo feminino & Ano \\
\hline Purpura & 1 & 0 & 2018 \\
\hline Esclerose múltipla & 1 & 1 & 2018 \\
\hline Artrite reumatóide & 0 & 1 & 2017 \\
\hline Doença celíaca & 4 & 3 & 2016-2018 \\
\hline \multicolumn{3}{|c|}{ Total } & 11 \\
\hline
\end{tabular}

Casos de doenças autoimunes (DAI), notificados em Toritama, entre 2016 e 2018.

O Hospital municipal de Toritama, registrou 10 ocorrências de DAIs, ao longo do triênio 2016 a 2018. Houve prevalência da doença celíaca nos 10 casos registrados. O predomínio dos casos foi em pacientes do sexo masculino.

\begin{tabular}{|c|c|c|c|}
\hline \multicolumn{2}{|l|}{ Doença celíaca } & \multicolumn{2}{|l|}{10} \\
\hline \multicolumn{4}{|c|}{ Diagnósticos de DAIs e de imunodeficiência primaria, por sexo e ano de diagnóstico. } \\
\hline Doença & Sexo masculino & Sexo feminino & Ano \\
\hline Doença celíaca & 4 & 1 & 2016 \\
\hline Doença celíaca & 1 & 0 & 2017 \\
\hline Doença celíaca & 2 & 2 & 2018 \\
\hline Total & & & 10 \\
\hline
\end{tabular}


Research, Society and Development, v. 10, n. 2, e50410212681, 2021

(CC BY 4.0) | ISSN 2525-3409 | DOI: http://dx.doi.org/10.33448/rsd-v10i2.12681

Casos de doenças autoimunes (DAI), notificados em Taquaritinga do Norte, entre 2016 e 2018.

O Hospital municipal de Taquaritinga do Norte, registrou 3 ocorrências de DAIs, ao longo do triênio 2016 a 2018. Os 3 casos registrados foram em pacientes do sexo feminino. Não havendo notificação na área da pesquisa no ano 2018.

\begin{tabular}{|c|c|c|c|}
\hline \multicolumn{2}{|l|}{ Purpura } & \multicolumn{2}{|l|}{1} \\
\hline \multicolumn{2}{|l|}{ Febre reumática } & \multicolumn{2}{|l|}{1} \\
\hline \multicolumn{2}{|l|}{ Doença celíaca } & \multicolumn{2}{|l|}{1} \\
\hline \multicolumn{4}{|c|}{ Diagnósticos de DAIs e de imunodeficiência primaria, por sexo e ano de diagnóstico. } \\
\hline Doença & Sexo masculino & Sexo feminino & Ano \\
\hline Purpura & 0 & 1 & 2016 \\
\hline Febre reumática & 0 & 1 & 2017 \\
\hline Doença celíaca & 0 & 1 & 2017 \\
\hline Total & & & 3 \\
\hline
\end{tabular}

Casos de doenças autoimunes (DAI), notificados em Garanhuns, entre 2016 e 2018.

\begin{tabular}{|c|c|}
\hline Anemia hemolítica & 1 \\
\hline Doença celíaca & 2 \\
\hline Lúpus eritematoso sistêmico & 1 \\
\hline Miosite & 2 \\
\hline Espondelite anquilosante & 18 \\
\hline
\end{tabular}

Diagnósticos de DAIs e de imunodeficiência primaria, por sexo e ano de diagnóstico.

\begin{tabular}{|c|c|c|c|}
\hline Doença & Sexo masculino & Sexo feminino & Ano \\
\hline Anemia hemolítica & & & 2017 \\
\hline Doença celíaca & & & $2017 / 2018$ \\
\hline Lúpus eritematoso sistêmico & & & 2016 \\
\hline Miosite & & & 2016 \\
\hline Espondelite anquilosante & & & $2016 / 2018$ \\
\hline Total & & & 24 \\
\hline
\end{tabular}

Casos de doenças autoimunes (DAI), notificados em Recife em 2019. 
Research, Society and Development, v. 10, n. 2, e50410212681, 2021

(CC BY 4.0) | ISSN 2525-3409 | DOI: http://dx.doi.org/10.33448/rsd-v10i2.12681

\begin{tabular}{|c|c|c|c|}
\hline Oftalmopatia de graves & \multicolumn{3}{|c|}{1} \\
\hline Alopecia aerata & \multicolumn{3}{|c|}{10} \\
\hline Artrite reumatóide & \multicolumn{3}{|c|}{2} \\
\hline Diabetes tipo 1 & \multicolumn{3}{|c|}{7} \\
\hline Doença de Graves & \multicolumn{3}{|c|}{4} \\
\hline Líquen plano & \multicolumn{3}{|c|}{2} \\
\hline Lúpus Eritematoso Sistêmico & \multicolumn{3}{|c|}{2} \\
\hline Pênfigo foliáceo & \multicolumn{3}{|c|}{2} \\
\hline Psoríase & \multicolumn{3}{|c|}{5} \\
\hline Tireoidite de Hashimoto & \multicolumn{3}{|c|}{5} \\
\hline Vitiligo & \multicolumn{3}{|c|}{6} \\
\hline \multicolumn{4}{|c|}{ Diagnósticos de DAIs e de imunodeficiência primaria, por sexo e ano de diagnóstico. } \\
\hline Doença & Sexo masculino & Sexo feminino & Ano \\
\hline Oftalmopatia de graves & 1 & 0 & 2019 \\
\hline Alopecia aerata & 1 & 9 & 2019 \\
\hline Artrite reumatóide & 0 & 2 & 2019 \\
\hline Diabetes tipo 1 & 2 & 5 & 2019 \\
\hline Doença de Graves & 1 & 3 & 2019 \\
\hline Líquen plano & 1 & 1 & 2019 \\
\hline Lúpus Eritematoso Sistêmico & 0 & 2 & 2019 \\
\hline Pênfigo foliáceo & 0 & 2 & 2019 \\
\hline Psoríase & 3 & 2 & 2019 \\
\hline Tireoidite de Hashimoto & 0 & 5 & 2019 \\
\hline Vitiligo & 0 & 6 & 2019 \\
\hline Total & & & 46 \\
\hline
\end{tabular}

Fonte: Autores.

É notória uma divergência em cada resultado de cada município, isso se deve a forma de disponibilidade desses dados, vale ressaltar a importância de uma padronização na organização desses dados. A cidade Santa Cruz do Capibaribe, representada pelo Hospital Raimundo Francelino Aragão, não registrou diagnósticos que se encaixasse na pesquisa durante o triênio selecionado, em estudo. 
O Diabetes Mellitus tipo 1, é uma doença autoimune bastante como comum, no entanto não pode ser explanada na pesquisa devido a um fator presente em todas as cidades em estudo. Os diagnósticos foram descritos com o CID E148, que engloba o tipo 1 e o tipo 2, não sendo possível diferenciá-las na pesquisa em estudo.

Após a triagem do quantitativo pesquisado e conferidos o diagnóstico pelo Código Internacional de Doenças- CID (Tabela 4) foram encontradas 8 de doenças autoimunes e 1 imunodeficiência primárias. Os 47 casos de DAI estão distribuídos da seguinte forma:

Tabela 3. CID- (Classificação internacional de doenças) das doenças autoimunes identificadas durante a pesquisa em unidades de saúde localizadas no interior de Pernambuco.

\begin{tabular}{|c|c|}
\hline Doenças autoimunes & CID \\
\hline Diabetes mellitus tipo 1 & E 05.9 \\
\hline Anemia de Heno chonclein & D 59.9 \\
\hline Purpura de imediato & D 69.3 \\
\hline Doença de celíaca & K 90.0 \\
\hline Lúpus eritematoso sistêmico & M32.9 \\
\hline Alopecia aerata & L63 \\
\hline Psoríase & L40 \\
\hline Vitiligo & L80 \\
\hline Líquen plano & L43 \\
\hline Pênfigo foliáceo & L10 \\
\hline Oftalmopatia de graves & H57 \\
\hline Doença de graves & E05.9 \\
\hline Tireoidite de Hashimoto & E06.3 \\
\hline Artrite séptica & M 00 \\
\hline Esclerose múltipla & G 35 \\
\hline Artrite reumatoide & M 06.9 \\
\hline Síndrome nefrótica & N 04.0 \\
\hline \multicolumn{2}{|c|}{ Imunodeficiência } \\
\hline Febre reumática & I 01 \\
\hline
\end{tabular}

Fonte: CID, DATASUS.

Embora não tenha sido um dos objetivos iniciais desta pesquisa, vale ressaltar que houve muitos entraves para a coleta dos dados, principalmente prontuários incompletos o que desfavoreceu para maior " $\mathrm{N}$ " nesta pesquisa. Para complementar os resultados, se reconhece a necessidade de uma descrição sumarizada das doenças constatadas. 


\subsection{Anemia hemolítica autoimune}

A anemia hemolítica autoimune (AHAI) é caracterizada pela destruição das hemácias antes do seu período de vida normal de 120 dias. Isto ocorre devido à fixação de auto anticorpos na superfície das membranas eritrocitárias, ocasionando a destruição via sistema complemento ou reticulo endotelial. As causas da AHAI são desconhecidas. A depressão do sistema imune através de ação viral e alteração dos antígenos de superfície dos eritrócitos por vírus ou drogas são algumas hipóteses para o aparecimento da doença (Oliveira et al., 2006).

A AHAI é classificada em quente, fria e mista, de acordo com a temperatura de reatividade dos anticorpos aos eritrócitos. $\mathrm{Na}$ AHAI quente os autos anticorpos quentes reagem em $37^{\circ} \mathrm{C}$ destruindo os eritrócitos pelo sistema reticulo endotelial. Na AHAI fria, os autos anticorpos frios reagem em $4-18^{\circ} \mathrm{C}$ causando morte eritrocitária através do sistema complemento. Na forma mista, os dois tipos de auto anticorpos estão presentes (Picon, 2013).

A anemia hemolítica também é classificada em primária e secundária. A AHAI primária não se identifica doença sistêmica para explicação da presença de auto anticorpos, apenas a anemia hemolítica. Já na secundária a AHAI é uma manifestação de uma doença sistêmica pré-existente. Pode acometer pacientes portadores de doença autoimune com lúpus eritematosos sistêmico. A doença também foi identificada em pacientes com neoplasias, como o linfoma de Hodgkin e nãoHodgkin e leucemia linfocítica crônica (Brunetta, 3016).

O diagnóstico é realizado pelo teste de Coombs direto positivo na presença de hemólise. Porém o teste pode apresentar resultado negativo ou falso positivo. Pode apresentar início agudo e rápida progressão como início retardado com evolução lenta, levando facilmente à cronicidade. (Oliveira et al., 2006)

O tratamento tem por objetivo diminuir o grau de hemólise, melhorando os sintomas e aumentando os níveis de hemoglobina. A identificação do tipo de AHAI é impreenchível pois os tratamentos são distintos. Caso seja AHAI secundária é necessário realizar o tratamento da doença base, seja suspendendo a utilização de fármacos que estão causando a hemólise ou realizando o tratamento de doenças linfo proliferativas ou doenças autoimunes associadas. Em casos extremos é realizada, se necessário a transfusão de hemácias, que deverá sempre ser precedida de administração ao paciente de corticosteroides, de preferência pulsoterapia com metilprednisolona e/ou da infusão de imunoglobulina intravenosa. (Cançado; Langhi; Junior; Chiattone, 2005).

\subsection{Espondilite anquilosante}

Espondilite anquilosante é uma doença inflamatória que atinge as articulações da coluna e as grandes articulações como as dos quadris e ombros. Esta doença está inclusa no grupo de doenças com características em comum, denominado: espondiloartropatias, subdivido em espondiloartropatia axial e periférica, para caracterizar melhor as patologias presentes no grupo. São consideradas duas variáveis para a espondiloartropatia axial (a sacroiliíte por imagem e/ou o antígeno de histocompatibilidade HLA-B27). A espondilite anquilosante se enquadra neste grupo. São observadas alteração de mobilidade espinhal e sacroiliíte com o avanço da patologia. Como complicação da doença os pacientes podem apresentar fraturas vertebrais. A causa da doença é desconhecida, porém, acredita-se que seja de origem genética (Sampaio-Barros et al., 2013).

Para o diagnóstico faz-se necessário o paciente atender pelo menos um dos seguintes critérios: História familiar positiva, psoríase cutânea, doença inflamatória intestinal, uretrite ou diarreia aguda até 4 semanas precedendo a artrite, dor em nádegas alternante, entesopatia e sacroilíte (Sampaio-Barros et al., 2007).

Para um tratamento eficaz faz-se necessário um diagnóstico precoce e preciso. Para isto autores sugerem que para o paciente ser diagnosticado com espondilite anquilosante ele deve possuir anquilose, ou seja, uma adesão fibrosa ou fusão óssea entre os componentes anatômicos da articulação, promovendo restrição nos movimentos (Ferreira et al., 2008). 
No tratamento da doença, apenas os anti-inflamatórios não-esteroides (ANES) e agente anti-TNF (inibidores do fator de necrose tumoral) são formas tratamento eficazes para espondilite anquilosante. Os anti-TNF expressaram importante efeito no paciente, reduzindo os sinais e sintomas da doença, melhoria da funcionalidade e da qualidade de vida, redução de provas de fase aguda e melhora da inflamação osteoarticular, e, os AINES inibem a atividade osteoblástica por meio do bloqueio de prostaglandinas.A inflamação e a neoformação óssea, apesar de estarem ligadas a doença, parecem ser adquiridos por hereditariedade. Para a prevenção da evolução radiológica da doença é necessário a atenuação precoce antes de danificações na cartilagem e erosões ósseas (Ferreira et al., 2008).

\subsection{Miosite}

As doenças reumáticas estão entre as mais prevalentes no mundo. Elas são caracterizadas principalmente por causar comprometimento funcional, incapacidade e dor. (RODRIGUES et al., 2019). As miopatias inflamatórias é um grupo heterogêneo de doenças sistêmicas por lesões mediadas imunologicamente e inflamação especialmente dos músculos esqueléticos proximais. São doenças raras, com incidência incerta e prevalência duas vezes maior no sexo feminino. (Jorge et al., 2017) Podem ter causas definidas como viral, bacteriana, parasitária, pela utilização de drogas entre outras, ou, erem idiopáticas como poliomiosite/miosite por corpúsculo de inclusão. Podem acometer o paciente de maneira isolada ou em associação com patologias sistêmicas como a esclerose sistêmica (Costa; Tavares; Nunes, 2008).

Há 3 distúrbios incluídos nesta categoria, que são: dematomiosite com envolvimento da pele e músculos esqueléticos, polimiosite, com falta do envolvimento da pele e miosite por corpúsculo de inclusão, com abrangência dos músculos distais, em destaque os extensores do joelho, flexores dos pulsos e dedos das mãos. Com a evolução da doença pode acontecer degeneração, atrofia e necrose das fibras musculares e depósitos de sais de cálcio. O caráter da doença é progressivo e seu acompanhamento é realizado pela clínica, estudo da função e forças musculares regressão ou remissão do eritema violáceo e outras manifestações na pele, avaliação da disfalgia, disfonia, regurgitação, enzimas sorológicas, eletroneuromiografia e pela ressonância nuclear magnética (Mota, et al.,2010).

O diagnóstico em pacientes com miopatia, devem ter relevância doenças que evoluam com algum tipo de lesão muscular e no quadro clínico de fraqueza muscular, exames laboratoriais com níveis de enzimas musculares eletroneuromiografia, biópsia muscular e a resposta que o paciente irá apresentar ao tratamento realizado no mesmo. A manifestação mais particular é a fraqueza muscular bilateral e simétrica, envolvendo a cintura escapular e pélvica. O comprometimento das atividades realizadas pelo paciente envolve a capacidade de levantar objetos acima do nível da cabeça, pentear os cabelos, recolher roupas do varal, subir escadas entre outras (Reis Neto; Pollak, 2008).

O tratamento tem por objetivo a melhoria da capacidade funcional do paciente e da qualidade de vida através do aumento da força muscular. Além de diminuir e retardar as surgimento de manifestações extra musculares. $\mathrm{O}$ tratamento de primeira escolha constitui-se no uso de corticosteroides com dose inicial de 60 a $100 \mathrm{mg}$ por dia de 3 a 4 semanas, com suscetível diminuição da dose utilizada pelo paciente. Também pode-se fazer a utilização de imunossupressores como a azatioprina de 2 a $3 \mathrm{mg} / \mathrm{kg}$ e o metotrexate, $25 \mathrm{mg} / \mathrm{sem}$ subcutâneo ou endovenoso, o mototrexate age mais rapidamente que a azatioprina. A plasmaferase é utilizada no tratamento de doenças auto-imunes para realizar a remoção de anticorpos circulantes e imunocomplexos. Estudos apontam que a imunoglobulina pode ser injetada junto com prednisona em pacientes com dermatomiosite e polimiosite apresentando melhora significativos (Reis Neto; Pollak, 2008).

\subsection{Diabetes mellitus tipo 1}

É uma doença metabólica crônica e atualmente sem cura, com grande prevalência na sociedade, principalmente em crianças e adolescentes. Seu desenvolvimento está relacionado com a destruição de células betas do pâncreas, cuja função é a 
síntese de insulina, para o controle glicêmico, porém devido esse processo autoimune, tem-se uma concentração de glicemia plasmática elevada, resultando no surgimento desse tipo de diabetes (Okido et al., 2017).

Ainda não se sabe a causa para o organismo atacar suas próprias células, mas acredita-se que fatores ambientais e genéticos podem estarem relacionados com o desenvolvimento da autoimunidade (Oliveira et al., 2018). Essa síndrome metabólica causa inicialmente, hiperglicemia e glicosúria, além de poliúria, polidipsia e perda de peso. Caso o tratamento não for iniciado poderá desenvolver complicações, como: desidratação e cetoacidose diabética (Maruichi et al., 2018).

Mesmo com as manifestações dos sinais e sintomas característicos do diabetes, a confirmação da patologia é feita através do exame laboratorial da hiperglicemia. Os principais exames são: glicemia aleatória, que não necessita de jejum, assim caso apresente maior que 200 miligramas por decilitro $(\mathrm{mg} / \mathrm{dL})$ de glicose, tem-se a comprovação da patologia. Outro tipo é o teste de glicemia realizado em paciente com um jejum mínimo de oito horas, a taxa de $126 \mathrm{mg} / \mathrm{dl}$ ou maior de glicose, com repetição do teste comprova DM (Brasil, 2019).

O tratamento é fundamental para garantir ao paciente uma qualidade de vida, assim é preciso manter a glicemia dentro dos padrões aceitáveis, através da terapia com insulina, mudanças nos hábitos alimentares e a prática de atividades físicas, para isso o paciente precisa adaptar sua nova rotina, pois a adesão ao tratamento é fundamental para assegurar bem-estar ao diagnosticado, evitando possíveis complicações (Greco-Soares \& Dell'Aglio, 2017).

\subsection{Púrpura de Henoch-Schonlein (PHS)}

É uma doença autoimune que causa inflamação nos vasos da pele, articulações, trato gastrointestinal e rins, causando petéquias que se tornam púrpura, artralgia, além de de provocar vômitos, dor abdominal e hemorragia gastrointestinal. A alteração renal provoca vários efeitos desde a hematúria microscópica até síndrome nefrótica. Sendo uma vasculite mais comum na infância, seu nome é decorrente da contribuição de dois cientistas, Johann Schönlein e Eduard Henoch em relação as manifestações clínicas desenvolvidas (Lopez et al., 2017).

Essa patogênese, é também conhecida como vasculite por IgA devido o acúmulo desses imunocomplexos nos vasos. Assim como outras doenças autoimunes, não possui etiologia definida, mas agentes infeciosos, fármacos e antigénios tumorais podem estarem vinculados com o desencadeamento, além de outros fatores. Seu diagnóstico é obtido por meio da clínica e exames histopatológicos (Gouveia et al., 2016).

\subsection{Púrpura Trombocitopênica Idiopática (PTI)}

É uma doença autoimune, de causa não definida, caracterizada pela produção de autoanticorpos pelo sistema imunológico responsável por atacar as plaquetas do próprio organismo, através da ligação em seus receptores, causando trombocitopenia, ou seja, diminuição dessas células, comprometendo o processo de coagulação sanguínea. Qualquer pessoa poderá desenvolver essa doença, pois não é especifica para sexo nem idade, porém é mais presente em mulheres na idade fértil (Agusto et al., 2016).

De acordo com o Protocolo Clinico e Diretrizes Terapêuticas, o diagnóstico é feito a partir do histórico clinico e exame físico, sendo de fundamental importância a realização de hemograma completo e esfregaço do sangue periférico. A confirmação da patogênese ocorre se houver trombocitopenia (menos de 100.000 plaquetas $/ \mathrm{mm}^{3}$, sem mudanças nas outras séries do sangue, bem como ausência de doenças que possam provocar a diminuição das plaquetas. Com isso, a PTI pode ser classificada em quatro fases, com base no diagnóstico. Caso tenha a confirmação em até 3 meses do seu desenvolvimento, se caracteriza em PTI recentemente diagnosticada, quando o diagnóstico é entre 3 a 12 meses, principalmente quando o paciente não consegue reverter a plaquetopenia de forma espontânea ou não responde bem ao tratamento no caso os refratários é nomeada de persistente. A PTI 
crônica é aquela que a confirmação da patogênese ocorre há mais de 12 meses e a grave está relacionada com a quantidade alta de sangramento, sendo necessário terapia imediata.

A diminuição das plaquetas poderá provocar no paciente petéquias, púrpura, hematomas e até um sangramento. Assim o tratamento inicial é feito a partir da administração de corticosteroides para aumentar a quantidade de plaquetas de forma imediata, além disso tem a imunoglobulina intravenosa que consiste na administração em altas doses e possui efeito rápido. A esplenectomia é indicada para adultos com a forma crônica caracterizada pela remoção do baço para evitar a destruição das plaquetas evitando sangramentos, porém esse procedimento poderá desenvolver vários efeitos indesejáveis (Provan \& Newland, 2015).

\subsection{Doença de celíaca}

Conhecida popularmente como intolerância ao glúten, se caracteriza como uma doença crônica, que ainda possui causa desconhecida, mas fatores ambientais, imunológicos e genéticos podem estarem vinculadas com seu desenvolvimento. Seu desencadeamento está relacionado com a ingestão de glúten, em grãos de trigo, cevada e centeio em pessoas geneticamente sensíveis, devido a presença de proteínas que induzem a ativação do sistema imune (Aflatoonian et al., 2019 ; Selleski et al., 2018).

Se caracteriza como uma doença autoimune, cujas células T e B do sistema imunológico produziram respectivamente, citocinas e anticorpos em resposta a presença do glúten no organismo. Sendo a presença dos anticorpos, $\operatorname{IgA}$ antitransglutaminase tecidual, anti-IgA-tTG, e os anti-endomísio no organismo que estão relacionados com o diagnóstico inicial, porém a confirmação é através da biópsia endoscópica duodenal ou jejunal (Selleski et al., 2018; Koc et al., 2017).

Essa enteropatia provoca alterações na mucosa do intestino delgado, porém afeta principalmente o duodeno e jejuno, podendo desenvolver manifestações clínicas relacionadas com sintomas intestinais, sendo caracterizada como a forma clássica, presente em sua maioria em crianças diagnosticadas, mas também sintomas extraintestinais, como déficit em ferro, além disso a presença da forma silenciosa e latente podem serem encontradas (Koc et al., 2017).

Devido a intolerância definitiva ao glúten, o tratamento do paciente consiste numa dieta livre de glúten (DLG). Embora o tratamento seja centrado na alimentação, ainda é difícil a adesão do paciente devido dificuldade de alternativas alimentares sem glúten e alto custo de produtos isentos desse composto (Queiroiz et al., 2017). Assim, a ingestão mesmo em poucas porções, poderá alterar a absorção dos nutrientes, tendo retardo no crescimento, além de constipação crônica, diarreias, dor e disten são abdominal, entre outros efeitos (Rocha et al., 2016).

\subsection{Esclerose múltipla}

A Esclerose Múltipla (EM) é uma doença crônica autoimune, caracterizada por lesões no Sistema Nervoso Central (SNC), onde a região afetada principalmente é a bainha mielina, que é uma proteína de fundamental importância na transmissão de impulsos nervosos. A destruição da mielina causa distúrbios na comunicação entre o cérebro e o corpo. Dados epidemiológicos retirados do sistema de informação de morbidade hospitalar (SIH), média de 2,5 milhões de pessoas em todo mundo, e no Brasil estima-se que aproximadamente 35 mil pessoas acometidas com essa doença, entre essas se tem 13 mil estão em tratamento atualmente no ano de 2014, estimasse que esses números tenham crescido com o decorrer dos anos (Datasus, 2014).

A etiopatolgenia dá EM se tem através de uma cascata de eventos, tendo envolvido a resposta imunológica adaptativa como um papel importante em seu desenvolvimento, também tem um processo degenerativo associado com a resposta imunológica aberrante do indivíduo (Bienes, 2014). 
No desenvolvimento da EM tem uma migração de linfócitos T, monócitos e outras células ao sistema nervoso central (SNC), esse passo é mediado por interação de proteínas de adesão expressas na superfície dos leucócitos com outras moléculas de adesão na superfície endometelial (P-selecitina), sendo que o bloqueio específico desta interação por fármacos é usado na terapia da EM como tem o bloqueio feito pelo anticorpo monoclonal natalizumabe a integrina linfocitária a4 b1 ao receptor VCAM-1 expresso na superfície endotelial da barreira hematoencefálica (Bienes, 2014).

Os linfócitos B, também participam desse processo imunológico na EM, onde desenvolver seu efeito de pró-inflamatório onde parece predominar seu efeito anti-inflamatório. Se tem a participação de agregados foliculares de células b nas meninges desses indivíduos acometidos com EM, essas meninges se correlacionam com lesões corticais mais extensas e idade de início de doença mais precoce, sugerindo que a difusão de fatores citotóxicos provenientes das meninges inflamadas possa ser um mecanismo associado a doença, se tem o uso de terapias onde seu foco é em modulação de células B está em estudo preliminar e parecem promissoras, porém seu papel e uso no bloqueio da evolução da doença ainda não foi completamente elucidado (Bienes, 2014).

Diante dessas cascatas desenvolvidas através da resposta inflamatória célula humoral causam as lesões diretamente a mielina e o axônio e promove a liberação de espécie reativa de oxigênio e o oxido de nítrico, o que pode levar a degeneração axonal e disfunção das mitocôndrias, desmielinização e apoptose de oligodendrócitos. Essa cascata pode ainda levar a ativação das metaloproteinases de matriz que é responsável por fragmentar a proteína da mielina, durante o desenvolvimento das lesões é liberado o ferro pelo o oligodendrócito degenerado, sendo captado pelas células da glia, que é capaz de potencializar o processo oxidativo (Bienes, 2014).

O diagnóstico é dado a partir dos sintomas apresentados pelo o portador mais o auxílio de exames de imagens, que podem ser ressonâncias magnéticas (do crânio e da coluna em nível cervical, torácico e lombar) e retirada do líquido cefalorraquidiano (LCR) O diagnóstico da esclerose múltipla EM, é obtido através de exames de ressonância magnética onde se consegue analisar as lesões no Sistema nervoso central (SNC), sendo capaz assim de avaliar o grau da doença, juntamente com o auxílio de exames de imagem, é preciso que haja uma correlação clinica desses portadores com o histórico clinico, o exame de LCR é de extrema importância, pois é possível fazer a pesquisa de banda oligoclonal (Fonte, 2016).

O tratamento medicamentoso visa reduzir a atividade inflamatória e os episódios de surtos ao longo da vida do paciente, existe uma restrição de alguns medicamentos que devem ser prescritos apenas por médicos neurologistas onde por sua vez ira fazer o acompanhamento do paciente de forma integral durante seu tratamento. Entre eles podem citar os imunomoduladores, imunossupressores, interferons e corticoides. Os imunomoduladores são aqueles que visam reduzir a inflamação e a deterioração da mielina, além da diminuição de surtos, contribuindo assim para o retardo da incapacidade corporal. Enquanto os imunossupressores reduzem a eficiência da atividade do sistema imunológico e por isso, eles vêm ganhando grande destaque no tratamento da Esclerose Múltipla (Vieira et al. 2018).

Os interferons são usados para reduzir o acontecimento de surtos e estabilizarem a doença. Eles são distribuídos de forma gratuita pelo governo no Brasil, diante de relatório médico que confirme a existência da doença. Já os corticoides que são administrados por via intravenosa possuem a intenção de diminuir os episódios de surtos (Vieira et al. 2018).

Uma visão atual para o tratamento da Esclerose Múltipla (EM) tem sido o uso medicinal da Cannabis sativa. No Brasil, o Mevatyl, em 2017, foi o primeiro medicamento com registro na AVISA. Ele apresenta dois elementos químicos: Canabidiol e Tetrahidrocanabidiol e ambos são encontrados na Cannabis sativa. O medicamento tem se mostrado eficaz e com boa tolerância no tratamento de dores neuropáticas e na redução da espasticidade (Anvisa 2018).

Em 2017 foi aprovado o primeiro medicamento de origem cannabis sativa no Brasil pela a agência nacional de vigilância sanitária (ANVISA), trata-se do mevatyl sua composição é de Tetraidrocanabinol (THC) e Canabidiol (CBD), o mevatyl é 
utilizado para o tratamento da espasticidade em pacientes com esclerose múltipla e seu uso vem sendo difundido mundialmente com o nome de Nabiximols (Anvisa 2018).

\subsection{Artrite reumatoide}

A Artrite Reumatoide (AR) é caracterizada uma DAI sistêmica, crônico degenerativa, que resulta em uma deformidade e destruição das articulações em virtude de erosões ósseas e da cartilagem, no Brasil, a prevalência de AR, em adultos está entre 0,5 a $1 \%$ da população em geral, o que significa uma taxa de incidência duas vezes maior que em mulheres, a população mais afetada em uma visão geral é indivíduos acima de 40 anos de idade (Sontag et al. 2017).

Atrite reumatoide é classificado como uma doença sistêmica inflamatória que é provocada pelo acúmulo de complexo antigo e anticorpo. A etiologia da doença ainda não está completamente esclarecida. Contudo, fatores ambientais e genéticos têm sido descritos contribuindo para o desenvolvimento dessa patologia (Barbosa et al 2019).

Em uma pessoa sem essa patologia, o sistema complemento onde os macrófagos, neutrófilos, células T (CD4 e TCD8) e células natural killer são responsáveis por desenvolver essa cascata e resultar assim em artrite reumatoide onde vai ser liberado a interleucina TNF- $\alpha$ e IL-1, que ocasiona a lesão articular. A AR é caracterizada basicamente por sinovite crônica, simétrica e erosiva, preferencialmente de articulações periféricas (Barbosa et al 2019).

Segundo Barbosa., et al (2019) A sinóvia das articulações afetadas é infiltrada por linfócitos T e B, macrófagos e granulócitos. A sinóvia reumatoide adquire características proliferativas, formando o pannus, e invade a cartilagem articular e o osso, levando à destruição da arquitetura normal da articulação e à perda de função. A diminuição da expressão de proteínas reguladoras do complemento (PCR) parece desempenhar papel importante na atividade da AR, associada ao agravamento dos sintomas clínicos. O aumento na ativação do sistema complemento (SC) é a causa da exacerbação da doença em vários modelos de doenças autoimunes.

$\mathrm{Na}$ AR, ocorre inicialmente a ativação da via clássica devido a presença de autoanticorpos, imuno complexo (IC), e células apoptóticas na articulação. Tem-se observado também o envolvimento da via alternativa devido à presença de fragmentos $\mathrm{Bb}$ no líquido sinovial. Esta via pode tornar-se ativa através do FR tipo Imunoglobulina A (IgA), presente em alguns pacientes com AR e/ou colágeno tipo-II, específico para a cartilagem, o qual é exposto como resultado da proteólise durante o curso da doença (Barbosa et al. 2019).

O diagnóstico da AR é baseado em achados clínicos e exames complementares, vale salientar que nenhum dos testes isolados confirma o diagnóstico. Dos exames laboratoriais utilizados para o diagnóstico da AR o classificado como padrão ouro (exame de referência) é o fator reumatoide (FR) e o anticorpo anti-peptídio citrulinado clínico (anti-CCP), esses testes possuem uma maior sensibilidade semelhante e especificidade superior à do FR (Oliveira et al. 2019).

Segundo o Consenso Brasileiro no Diagnóstico e Tratamento da Artrite Reumatóide, o diagnostico laboratorial para a AR é emitido através de uma base de critérios para fazer uma análise minuciosa. É realizada uma avalição no período de rigidez matinal, e na intensidade da dor articular e se tem alguma limitação na função. Outro critério avaliado é o exame físico onde se tem o número de sítios anatômicos afetados e o exame laboratorial que é de suma importância onde é solicitado um Hemograma, Velocidade de hemossedimentação e/ou proteína $C$ reativa, prova função renal, dosagem de enzimas hepáticas e exame qualitativo de urina, dosagem do fator reumatoide que é o marcado específico para a AR e, por fim, a análise do líquido sinovial. Outro método para auxiliar no diagnóstico é a radiografia das articulações comprometidas. Ainda de acordo com esta mesma fonte, o tratamento paliativo dar-se, principalmente por drogas inibidoras de TNF, fisioterapia e terapia ocupacional (Vieira et al. 2018).

Para que se tenha um tratamento mais efetivo, é de extrema importância que se tenha um diagnóstico quando precoce melhor e em seguida a interversão adequada, o que é possível impedir os danos articulares antes que se tornem totalmente 
irreversíveis. Os tratamentos incluem; uma abordagem multidisciplinar, medicamentosa, cirúrgicas e fisioterapia (Wibelinger 2019).

Os principais objetivos do tratamento incluem: promover uma diminuição da atrofia e fraqueza muscular, realizar um alongamento muscular e do tecido conectivo, manter elou aumentar a amplitude de movimentos, redução dos edemas, melhorar a resistência aeróbica, evitar posições viciosas e promover um condicionamento cardiopulmonar (Wibelinger 2019).

Os primeiros dozes meses da doença é considerado uma "janela de oportunidade" onde pacientes tratados nesse período apresenta melhores prognósticos. No Brasil os medicamentos são financiados pelo o sistema único de saúde (SUS) os medicamentos utilizados durante o tratamento apresentam alto custo, por esse motivo é de extrema importância outras formas de tratamento como o acompanhamento de fisioterapeutas (Silva et al. 2018).

Dentro do grupo das doenças reumáticas, a AR é o tipo mais comum que afeta a população brasileira, entre 2010 a 2011, foram registrados 33.852 internamentos de pacientes em decorrência a enfermidade. O grupo do sexo feminino é o mais atingido por essa patologia e a faixa etária de idade mais atingida varia entre 30 a 40 anos de idade (Saúde, 2017).

Dentro desse grupo de mulheres a maioria inclui; idade avançada, obesidade, tabagismo, consumo de bebidas alcoólicas e o excesso e ingestão de medicamentos que podem contribuir para o desencadeamento dessa doença (Saúde, 2017).

O ministério da saúde preconiza a importância de logo após a identificação dos sintomas que esses portadores possam procurar os serviços de saúde mais próximo para que possa ser submetido a exames laboratoriais e caso seja confirmado se inicie a interversão adequada que é de extrema importância como já foi citado anteriormente.

Os sinais e sintomas suspeitos de AR são dor nas articulações que se prolongue mais de seis semanas, e o surgimento de vermelhidão, inchaço, calor elou dificuldade para movimentar as articulações no período da manhã (Saúde 2017).

Segundo o ministério da saúde, o problema pode ser identificado pelo o próprio paciente, uma vez que a pessoa sempre venha sentir dores ao esticar os braços ou elevar os ombros até encostar-se ao pescoço. É preciso atenção vale ressaltar mais uma vez a importância do diagnóstico precoce e o tratamento adequado o que diminui os riscos de incapacidade física.

\subsection{Espondilite anquilosante}

A espondilite anquilosante (EA) se aplica a classificação de doenças inflamatórias conhecidas como espondiloartropatias, evidenciam particularidades epidemiológicas, clínicas anatomopatológicas, radiológicas e imunogenéticas comuns, atualmente são intituladas espondiloartrites. As espondiloartrites constituem a EA, a artrite reativa (normalmente conhecida como Síndrome de Reiter), a artrite psoriásica, a espondiloartrite associada à doença inflamatória intestinal e a espondiloartrite indiferenciada. A EA é de natureza inflamatória, crônica e evolutivo afetando primeiro as articulações sacroilíacas assim como também o esqueleto axial, atinge escassamente as articulações periféricas e outros órgãos extra articulares, como olho, pele e sistema cardiovascular. Durante os primeiros anos da doença, existem perdas funcionais (Gouveia et al.,2012).

Os sintomas são percebidos no final da adolescência ou na primícia da idade adulta, depois dos quarenta anos de idade é incomum; dentre todas as reclamações, lombalgia é o mais universal, precoce e com dificuldade de localização, se propaga para a região glútea profunda e linha articular das sacro-ilíacas na maioria das vezes de aspecto bilateral, ocasionando uma incapacidade por causa de um congelamento das vértebras da coluna que com o tempo, dificultam um simples passo. São caracterizadas pela formação de dores na coluna de forma vagarosa por algumas semanas, com piora após o repouso e dentre alguns meses se torna assídua contendo rigidez e há noção de dor na região lombar (Avante, 2007).

Para o diagnóstico da EA, não há um teste laboratorial, a grande quantidade de pacientes tem indícios de atividades inflamatórias, esses indícios aparecem nos períodos de doença ativa, elevação da velocidade de hemossedimentação, proteína creativa, crescimento da quantidade de IgA sérica (Avante, 2007). 
O tratamento para esta doença pode ter várias classificações como, por exemplo, medicamentoso, intervenções cirúrgicas e reabilitação, dentre a classificação de reabilitação pode ser citado a fisioterapia, terapia ocupacional, suporte psicológico e educação ao indivíduo doente; essa educação inclui atividades programadas para aprimorar o comportamento para com a saúde, melhorando seu quadro com resultados em longo tempo (Souza et al., 2012).

\subsection{Lúpus eritematoso}

A doença conhecida como Lúpus eritematoso sistêmico (LES) é uma patologia autoimune sistêmica na qual tem atributos como produção de autoanticorpos, formação e deposição de imunocomplexos, inflamação em vários órgãos e dano tecidual. Não se conhece muito a sua origem, mas é conhecido que para a existência da doença, porém sabe-se da participação de fatores hormonais, ambientais, genéticos e imunológicos para o surgimento da doença. Podem ser mencionados atributos clínicos polimórficos, com momentos de exarcebação e remissão. A doença pode decorrer com sintomas como artrite, serosite, nefrite, vasculite, miosite, manifestações mucocutâneas, hemocitopenias imunológicas, inúmeros quadros neuropsiquiátricos, hiperatividade reticuloendotelial e pneumonite. (Freitas, 2019).

O LES é mais constante em mulheres segundo alguns estudos, em uma escala de nove mulheres para cada homem, tendo maior ocorrência entre 15 e 45 anos, no Brasil não existe muitos estudos relacionando o acontecimento de casos na população. (Araújo et al., 2007) Nem todas as pessoas lidam bem com a doença crônica e principalmente com seus sintomas, personalidade, grau de maturidade, entre outros; podem influenciar o ponto de vista para com essa doença, já que cada indivíduo age de acordo com o pensamento que está inserido. (Silva, et al.,2013)

Para o diagnóstico da doença, é preciso se apoiar nos sintomas; o órgão afetado e os exames também podem ajudar no reconhecimento, o profissional que irá realizar a análise precisa reconhecer os critérios da doença e a solicitação de exames varia por indivíduo (Freirtas, 2019).

O tratamento é muito variado o que torna difícil a aceitação do paciente, o que está sendo utilizado para o controle da doença são medicações, que no decorrer do período de atividade são adequados segundo as manifestações clínicas e o nível da doença, o procedimento para com a grande maioria dos pacientes com a doença reduz a inflamação, soluciona os sintomas, volta a estabelecer as funções do organismo que estavam prejudicadas (Narciso, Lourdes, 2014).

\subsection{Febre reumática}

A febre reumática (FR) é ocasionada pelo estreptococo beta-hemolítico do grupo A (Streptococcus pyogenes), onde causa um problema não supurativo na faringoamigdalite, deriva da resposta imune demorada em populações geneticamente predispostas. Nos dias de hoje variam-se 500.000 novos casos de FR com prevalecimento de 15 milhões de caso de cardite reumática. No Brasil, as informações sobre FR são poucas, mas há consciência que em torno de 233.00 indivíduos morrem por causa dessa doença, na América Latina acontece anualmente cerca de 21.000 casos de FR aguda (Peixoto, et al., 2011).

Tem por características como lesões inflamatórias, não supurativas, envolvendo o tecido cardíaco, as articulações, o tecido celular sub-cutâneo e o sistema nervoso central, pessoas que sofrem da febre reumática podem ter outros sintomas por causa das infecções estreptocócicas, subseqüentes, das vias aéreas superiores (Souza et al., 2015).

O diagnóstico de FR é normalmente clínico, e os exames que são adicionais servem para assegurar alguma atividade inflamatória, na maior parte há uma verificação para confirmar uma infecção estreptocócica para ajudar na supervisão da terapia, existem critérios no diagnóstico que são apenas um complemento para auxiliar, já que não há testes laboratoriais, sinais e até mesmo sintomas que isolados sejam característicos da febre reumática (Sztajnbok et al.,2001).

O tratamento da FR pode consistir em etapas como, por exemplo, o tratamento sintomático e o profilático, o profilático tem base em evitar o aparecimento da FR depois de um episódio de angina estreptocócica, e a profilaxia secundária, 
que tem como finalidade impossibilitar novos surtos nos pacientes que já houve um surto da enfermidade; o sintomático tem base em medicamentos como anti-inflamatórios, ácido valpróico, fenobarbital, benzodiazepínicos e sulpiride (Sztajnbok et al., 2001).

\subsection{Tireoidite de Hashimoto}

A Tireoidite de Hashimoto (TH) é classificada como pertencente grupo do hipotireoidismo afetando a tireoide uma glândula responsável pela produção de hormônios que são de grande importância ao corpo humano, onde há uma maior incidência no sexo feminino, dita como autoimune pois o próprio indivíduo inicia a produção de anticorpos que vão atacar a tireoide ou seja o organismo acaba reconhecendo a tireoide como um "corpo estranho" e produz anticorpos para acabar com essa glândula (Maldini, 2019).

No hipotireoidismo os hormônios não estão sendo produzidos de forma suficiente na glândula tireoide. A tireoide interage com outros órgãos do corpo sendo também responsável pela produção dos hormônios de cada um deles, vale ressaltar que a dosagem dos hormônios T3 e T4 deve ser levada em consideração pois os resultados dos seus níveis juntamente com o resultado do THS irão determinar o estágio ou seja como encontra-se a evolução do hipotireoidismo (Maldini, 2019).

O exame a ser feito para o diagnóstico da Tireoidite de Hashimoto é a ultrassonografia por ser um método de melhor visibilidade da glândula. Para o tratamento da tireoidite de Hashimoto os hormônios tireoidianos que se encontram em quantidades mínimas são administrados no paciente (Junior et al., 2017).

\subsection{Psoríase}

A Psoríase é uma afecção cutânea crônica autoimune (não contagiosa) onde as lesões podem apresentar graus distintos, ocorrem na maioria dos casos em pacientes com idade mais avançada, mas podem sim ocorrer em crianças e jovens. A Psoríase pode aparecer em várias partes do corpo como em unhas que corresponde a um estado mais grave da doença, couro cabeludo, face entre outras, vale ressaltar que em média $70 \%$ dos casos de psoríase são consideradas lesões de grau leve (Dopytalska et al., 2018).

Pacientes com psoríase apresentam uma facilidade para o desenvolvimento de algumas doenças dentre elas o diabetes e até mesmo a depressão em razão do preconceito voltado a essa patologia, a pele descamada, irritada as manchas de um modo em geral que esses pacientes apresentam acabam os deixando com uma baixa autoestima onde começam a evitar de frequentar lugares ou até mesmo interrompem seus ciclos de amizade com receio de serem julgados (a) pelas lesões no corpo e também por uma questão de falta de informação por pensar que é uma doença contagiosa, isso afeta o psicológico e comportamento do paciente (Michalek et al 2016).

Fatores como o tabagismo, estresse e até mesmo um histórico familiar podem contribuir para o desenvolvimento e aumentar gravidade da doença, é importante lembrar que a Psoríase é uma patologia de origem desconhecida, no entanto há uma correlação com o sistema imunológico (SBD).

O tratamento é iniciado após o diagnóstico da gravidade em que a doença se encontra, ou seja, cada grau corresponde a um diferente tipo de tratamento, corticoides tópicos, análogos da vitamina D são alguns medicamentos utilizados em casos leves, a fototerapia é aplicada de casos moderados a mais graves, é indicada que ela seja a primeira terapia a ser empregada no tratamento e mesmo após algumas sessões e a fototerapia não estiver sendo eficaz outros medicamentos são administrados (Diniz, 2020). 


\subsection{Doença de Graves}

A Doença de Graves (DG) é uma doença tireoidiana que ocorre por uma "desordem" do sistema imunológico, onde as células de defesa do corpo atacam essa glândula, os anticorpos atacam o receptor de TSH portanto é classificada como um hipertireoidismo, a tireoide cresce e os hormônios produzidos por essa glândula apresentam-se em alta assim outros órgãos do corpo humano passam a ser afetados devido a essa alta de hormônios (T3 e T4) (Gardoni et al.,2017).

A faixa etária predominante da doença está em mulheres com até os 40 anos de idade sua sintomatologia geralmente é caracterizada por taquicardia (batimentos cardíacos desregulados/ aumentados), fadiga, insônia, menstruação desregulada, entre outros. A Iodoterapia é um método de tratamento utilizado na doença de graves assim fazendo com que a tireoide reduza a carga hormonal em produção, medicamentos também são indicados para a realização do tratamento como antitireoidiano e betabloqueador (Cruz, 2018; Daré, 2019).

\subsection{Vitiligo}

O Vitiligo é classificada como uma doença cutânea crônica autoimune que pode afetar várias partes do corpo do portador, de fácil percepção devido a pele apresentar-se despigmentada e com manchas quem podem variar de tamanho justamente por esse aspecto que existe um preconceito voltado a essa patologia, os portadores enfrentam dificuldades diárias para lhe dar com outras pessoas, nos ciclos de amizade e até mesmo a vergonha de saírem de casa em busca de um tratamento (Bú, 2017).

As manchas ocorrem devido a morte/destruição dos melanócitos (localizam-se na epiderme) que são células humanas produtoras da melanina que é responsável pela pigmentação, ou seja, pela cor de pele, com essa destruição dos melanócitos não há produção da melanina e consequentemente alteração na coloração da pele (Franken et al.,2020).

Essa doença é prevalente em cerca de $0,38 \%$ a 2,9\% em todo o mundo variando sua incidência de um pais para o outro, as manchas que são vistas a olho nu na pele possuem várias formas de tratamento devido ao quadro clinico de cada portador que incluem fármacos, a fototerapia entre outros métodos, vale ressaltar que quando o aparecimento das manchas se iniciam quanto mais rápido um tratamento for empregado melhor resultado o paciente terá, assim melhorando sua autoestima e seu convívio em meio social. No início da manifestação da doença as manchas aparecem de forma sutil em regiões geralmente mais expostas como mãos e cotovelos, mas podem ser confundidas até com uma alergia (Franken et al., 2020; Mendoça et al.,2020).

\subsection{Líquen Plano}

O Líquen Plano (LP) é uma doença de classificação mucocutânea, ou seja, pode afetar mucosas, região genital, região oral entre outros, podendo demostrar-se sobre cada órgão afetado de forma distinta como as lesões bolhosas, eritematosas entre outras na região bucal, feridas e bolhas na parte genital, o aparecimento dessa doença se dá através do sistema imune que entra em ataque com as mucosas, e com a pele (Leite et al.,2019; Rebelo,2019).

O diagnóstico do Líquen é realizado através do exame histológico, biópsia, as lesões geralmente apresentam- se assintomáticas, assim dependendo da região em que se encontra pode ser mais difícil pelo paciente de identificá-la (Silva,2017).

Doença predominante em indivíduos adultos na média de $2 \%$ sendo mais prevalente no sexo feminino, o tratamento do Líquen plano é realizado geralmente com corticoides sendo receitado e monitorado seu uso sempre por um médico, mais em casos mais graves o tratamento com a fototerapia também é realizado (Rebelo,2019; Ribeiro, 2019). 


\subsection{Oftalmopatia de Graves}

A Oftalmopatia de Graves (OG) é classificada como uma doença de caráter inflamatório autoimune que compromete a visão do indivíduo, os músculos extraoculares que têm função de controlar o movimento dos olhos crescem, ou seja, os músculos ficam hipertróficos, acontece devido a uma reação de linfócitos (T) e anticorpos da região ocular (Rocha et al.,2019).

A prevalência da doença são indivíduos adultos/idosos do sexo feminino, para o diagnóstico da OG exames de imagens são bastante essenciais para uma visualização da órbita e suas possíveis alterações como a ressonância magnética, é importante lembrar que após o diagnóstico o grau da doença e seu desenvolvimento devem ser levados em consideração antes de decidir qual melhor tratamento deve ser empregado (Rodrigues et al.,2015).

Os tratamentos podem ser desde anti-inflamatórios, sessões de radioterapia em graus mais elevados em que o paciente estiver fazendo radioterapia as sessões são feitas com menor intervalo de tempo de uma para outra, uso de glicocorticoides, iodo radioativo (Rodrigues et al.,2015; Jampaulo, 2018).

\subsection{Pênfigo foliáceo}

O pênfigo foliáceo (PF) é uma patologia autoimune em que se originam bolhas na pele do indivíduo em razão da produção da imunoglobulina IgG que tem como finalidade interagir com uma glicoproteína adesão intercelular que acaba sendo expressa na epiderme assim ocasionando lesões (James,2011).

\section{Conclusão}

O levantamento de DAI e IDP no Agreste de Pernambuco, contemplou a estimativa de casos nas cidades Recife, Garanhuns, Toritama, Taquaritinga do Norte, Santa Cruz do Capibaribe e Limoeiro. Foram identificados 94 diagnósticos, sendo 93 DAI e 1 IDP. Totalizando 18 doenças autoimunes, onde a maior prevalência foi Doença Celíaca, seguida de Espondilite Anquilosante com 19 e 18 portadores, respectivamente. Garanhuns foi a cidade com maior número de diagnostico, com maior índice no ano de2016.

Durante a realização da pesquisa encontrou-se dificuldades tanto para a coleta dos dados pela falta de legibilidade dos prontuários com, ainda pela falta de abertura de alguma US com a não permissão para a coleta dos dados. As IDP representam um grande desafio em seu diagnóstico e tratamento. Seu prognóstico depende, sobretudo, do reconhecimento precoce dessas doenças. É de extrema importância que o pediatra esteja atento aos principais pontos de alerta para se pensar em IDP. Finalmente, considera-se o desenvolvimento de mais pesquisas direcionadas ao levantamento de DAIs e IDPs, para a publicação de dados epidemiológico sobre esses grupos de doenças, no Brasil e no mundo.

\section{Referências}

Aflatoonian, Majid et al. Associações de polimorfismos IL-6 -174G>C e IL-10 -1082A>G com suscetibilidade à doença celíaca: evidências de uma metaanálise e revisão de literatura. Arq. Gastroenterol., São Paulo, v. 56, n. 3, p. 323-328, set. 2019. http://www.sbmdn.org.br/leiaepublique/Numero-1-JaneiroMarco-2019-Volume-56-1.pdf

Almeida, F.P., Ferreira, E. A. P., Moraes, A. J. P. (2017). Efeitos de Registros de Automonitorização sobre Relatos de Adesão ao Tratamento em Adolescentes com Lúpus. Psicologia: Teoria e Pesquisa, 33(1), <https://periodicos.unb.br/index.php/revistaptp/article/view/19471>

Anvisa. (2017). Esclerose múltipla tem novo tratamento aprovado. Portal da Anvisa. Notícias. <portal.anvisa.gov.br/noticias/-/asset_publisher/.../esclerosemultipla-tem.../219201>.

Araújo, A D. \& Traverso-Yépez, M. A. (2007). Expressões e sentidos do lúpus eritematosos sistêmicos (LES). Estudos de Psicologia, $12(2), 119-27$.

Avante, A. (2007). Aplicação de Water Pilates no tratamento da espondilite anquilosante. São Samuel.

<https://www.scielo.br/scielo.php?script=sci_abstract\&pid=S1413-294X2007000200003\&lng=en\&nrm=iso\&tlng=pt: 
Barbosa, M. G. A., Santos, S. M. \& Lins, S. R. O. (2019). Fator desencadeante da artrite reumatoide, formas de diagnostico e opções terapêuticas para o tratamento: um relato de caso. A Produção do Conhecimento nas Ciências da Saúde 5. 5ed.: Atena Editora, 2019, v. , p. 133-140. https://www.atenaeditora.com.br/wp-content/uploads/2019/05/e-book-A-Producao-do-Conhecimento-nas-Ciencias-da-Saude-5.pdf

Barros, L. C. S. et al. (2017). Doença celíaca silenciosa e latente em crianças e adolescentes com doenças reumáticas autoimunes. <http://www7.bahiana.edu.br/jspui/handle/bahiana/3079>

Bezerra, O. M. P. A. et al. (2017). Pênfigo Foliáceo Endêmico (Fogo Selvagem) e sua associação com fatores ambientais e ocupacionais em Ouro Preto, Minas Gerais, Brasil. Cadernos Saúde Coletiva, 25(2), 225-32. <https://www.scielo.br/scielo.php?pid=S1414 $462 X 2017005002106 \&$ script $=$ sci_abstract\&tlng=pt>.

Bienes, G., Oliveira, E. M. L. \& Denis, B. (2014). Esclerose múltipla. Multiple Sclerosis. Rev Bras Med, 71(12), $37-45$.

Brasil. (2011). Osteoartrite (Artrose). Sociedade Brasileira de Reumatologia. São Paulo. <https://pesquisa.bvsalud.org/portal/resource/pt/biblio-2482>.

Brunetta, D. M. (2016).Prevalência e fatores de risco para hemólise imune nos pacientes submetidos a transplante hepático. <http://repositorio.ufc.br/handle/riufc/22213>.

Bú, E. A. D., Alexandre, M. E. S. \& Coutinho, M. P. L. (2017). Representações sociais do vitiligo elaboradas por Brasileiros marcados pelo branco. Psicologia, Saúde \& Doenças, 18(3), 760-72. <http://www.scielo.mec.pt/scielo.php?script=sci_abstract\&pid=S1645$00862017000300011 \& \operatorname{lng}=$ pt\&nrm=iso>.

Cançado, R. D., Langhi Jr., D. M. \& Chiattone, C. S. (2005). Tratamento da anemia hemolítica auto-imune. Arquivos Médicos dos Hospitais e da Faculdade de Ciências. Médicas da Santa Casa de São Paulo, 2(50), 56-60. http://arquivosmedicos.fcmsantacasasp.edu.br/index.php/AMSCSP/article/view/433/0

Clínico, Protocolo; Terapêuticas, Diretrizes. Lúpus eritematoso sistêmico. Protocolos clínicos e diretrizes terapêuticas, p. 353. <http://bvsms.saude.gov.br/bvs/saudelegis/sas/2013/prt0100_07_02_2013.html>

Coimbra, I. B. et al. (2004). Osteoartrite (artrose): tratamento. Revista Brasileira de Reumatologia, 44(6), 450-3. <https://www.scielo.br/scielo.php?pid=S0482-50042004000600009\&script=sci_abstract $>$.

Costa, A. L. P., Silva-Júnior, A. C. S. \& Pinheiro, A. L. (2019). Fatores associados à etiologia e patogenese das doenças autoimunes. Arquivos Catarinenses de Medicina, 48(2), 92-106. <http://www.acm.org.br/acm/seer/index.php/arquivos/article/view/347>.

Costa, L. F. C., Tavares, F. F. P. \& Nunes, M. L. Á. (2008). Miopatias inflamatórias idiopáticas. Relato de caso*. Revista Brasileira de Clínica Médica, Belo Horizonte, 7(1), 53-5. <http://files.bvs.br/upload/S/1679-1010/2009/v7n1/a53-55.pdf>.

Da Cruz, M. C. \& Paiva, G. P. (2018). Miastenia Gravis em associação à Dermatomiosite e Doença de Graves: relato de caso. Archives of health investigation, 7(2). <https://archhealthinvestigation.com.br/ArcHI/article/view/2405>.

Da Silva Júnior, I. A., De Oliveira Dourado, C. A. R. \& Da Silva, M. I. S. (2020). Perfil de pacientes com neuromielite óptica em tratamento com rituximabe. Revista Eletrônica Acervo Saúde, 56, e3953-e3953. < https://acervomais.com.br/index.php/saude/article/view/3953>.

Daré, G. O. \& Pirozzi, F. F. (2019). Esquema de bloqueio e substituição no tratamento da doença de graves: relato de caso. Revista Corpus Hippocraticum, 1(1), <http://revistas.unilago.edu.br/index.php/revista-medicina/article/view/198>.

Datasus. (2014). Pesquisa com dados do DATASUS sobre mobilidade em pacientes com esclerose múltipla é um dos destaques do $15^{\circ}$ Encontro Anual de Esclerose Múltipla BCTRIMS 2014. Publicado em 08 de agosto 2014. <http://datasus.saude.gov.br/noticias/atualizacoes/506-pesquisa-com-dados-do-datasussobre-mobilidade-em-pacientes-com-esclerose-multipla-e-um-dos-destaques-do-15-encontro-anual-de-esclerose-multipla-bctrims-2014> .

De Medeiros, A K. M. et al. (2016). Púrpura trombocitopênica idiopática. Corpus et Scientia, 11(2), 69-78. <https://silo.tips/download/purpuratrombocitopenica-idiopatica>.

De Souza Duarte, V. et al. (2017). Exercícios físicos e osteoartrose: uma revisão sistemática. Fisioterapia em Movimento, 26(1). $<$ https://www.scielo.br/pdf/fm/v26n1/22.pdf >.

De Souza Rocha, A. et al. (2019). Aspectos radiológicos na avaliação da Oftalmopatia de Graves: uma revisão de literatura. Revista de Medicina e Saúde de Brasília, 7(2). <https://portalrevistas.ucb.br/index.php/rmsbr/article/view/8988>.

De Souza, M. C. et al. (2012). Grupos educacionais para pacientes com espondilite anquilosante: revisão sistemática. Rev Dor, 13(4), 256-60. <https://www.scielo.br/scielo.php?pid=S1806-00132012000300011\&script=sci_abstract\&tlng=pt>.

Diniz, M. (2020). Psoríase: Recomendações atuais do tratamento. Publicado no website da UniBH.

https://www.acoesunimedbh.com.br/sessoesclinicas/wordpress/wp-content/uploads/2020/03/Psoriase-FINAL-UNIMED.pdf.

Dopytalska, K. et al. (2018). Psoríase em localizações especiais. Reumatologia 56,6: p.392-398. doi: 10.5114 / reum.2018.80718. https://school2033.ru/pt/the$<$ help-you-need-to-best-manage-your-psoriasis-or-psoriatic-arthritis/>.

Erreira, A. L. M. et al. (2008). Consenso Brasileiro de Espondiloartropatias: Espondilite Anquilosante e Artrite Psoriásica Diagnóstico e Tratamento Primeira Revisão. Revista Brasileira de Reumatologia, Belo Horizonte, 48(4), 243-7. <https://school2033.ru/pt/the-help-you-need-to-best-manage-yourpsoriasis-or-psoriatic-arthritis/>.

Fillis, M. M. A et al. 2018). Incontinência Urinária em pessoas com Esclerose Múltipla: estudo transversal. Hórus, 13(10, 1-13.

<http://periodicos.estacio.br/index.php/revistahorus/article/view/4558>. 
Fonets, C. C. C. \& De Arruda Souza, T. (2016). Esclerose múltipla: diagnóstico por imagem e achados laboratoriais. UNILUS Ensino e Pesquisa, 13(30), 197. <http://revista.unilus.edu.br/index.php/ruep/issue/view/30>.

Franken, I. et al. (2020). Vitiligo conceitos e patogenia: uma revisão bibliométrica. In: $13^{\circ}$ Congresso Nacional de Psicologia da Saúde-Actas. Edições ISPA, 2020. p. 813-21. <http://repositorio.ispa.pt/handle/10400.12/7616>.

Freitas, E. C. (2019). Avaliação da suplementação de vitamina D no desenvolvimento e evolução de lúpus eritematoso sistêmico em modelo experimental. <https://www.lume.ufrgs.br/handle/10183/198416>

Gardoni, L. D. et al. (2017). Hipertireoidismo da doença de graves: um relado de caso. Revista de Ciências, 8(1). <http://bibliotecadigital.unec.edu.br/ojs/index.php/revistadeciencias/article/view/471/571>.

Gouveia, A. I., Lopes, L. \& Freitas, J. P. (2016). Púrpura de Henoch-Schönlein (Vasculite por IgA) no Adulto. Revista da Sociedade Portuguesa de Dermatologia e Venereologia (SPDV). <https://docplayer.com.br/79838946-Purpura-de-henoch-schonlein-vasculite-por-iga-no-adulto-henoch-schonleinpurpura-iga-vasculitis-in-adults.html>.

Gouveia, E. B., Elmann, D. \& Morales De Ávila, M. S. (2012). Espondilite anquilosante e uveíte: revisão. Rev. Bras. Reumatol, 52(5), 749-56. $<$ https://www.scielo.br/scielo.php?script=sci_arttext\&pid=S0482-50042012000500009>

Greco-Soares, J. P. \& Dell'aglio, D. D. (2017). Adesão ao tratamento em adolescentes com diabetes mellitus tipo 1. Psicologia, Saúde \& Doenças, 18(2), 322-34. <http://www.scielo.mec.pt/scielo.php?script=sci_abstract\&pid=S1645-00862017000200004\&lng=pt\&nrm=iso>.

James, K. A, Culton, D. A. \& Diaz, L. A. (2011). Diagnosis and clinical features of pemphigus foliaceus. Dermatol Clin. $<$ https://pubmed.ncbi.nlm.nih.gov/21605805/>.

Jampaulo, M. (2020). Oftalmopatia de graves: entenda o que é. Website: Viva Oftamologia. <https://vivaoftalmologia.com.br/oftalmopatia-de-gravesentenda-o-que-e-o-problema/>.

JUNIOR, C. A. R. et al. (2017). Síndrome de Turner, Tireoidite de Hashimoto e doença de Crohn em irmãs: relato de caso. Revista de Patologia do Tocantins, 4(4), 29-33. <https://sistemas.uft.edu.br/periodicos/index.php/patologia/article/view/4620>.

JÚNIOR, H. M. M. (2013). Terapêuticas, p. C. E. D., \& autoimune, A. H. PORTARIA No-1.308, DE 22 DE NOVEMBRO DE 2013. <http://bvsms.saude.gov.br/bvs/saudelegis/sas/2013/prt1308_22_11_2013.html>.

KOC, Gonca et al. (2017). Magnetic resonance enterography in pediatric celiac disease. Jornal de pediatria, 93(4), 413-9. <https://www.scielo.br/scielo.php?pid=S0021-75572017000400413\&script=sci_abstract >.

Leite, R. B. et al. (2019). Líquen plano oral: manifestações clínicas e diagnóstico. Revista Ciências e Odontologia, 3(2), 9-14. <http://revistas.icesp.br/index.php/RCO/article/view/708>.

Lopes, F. S. C. (2018). Estudo da prevalência de doenças autoimunes não-tireoidianas e da positividade dos auto-anticorpos relacionados ao diabetes mellitus tipo 1 e à doença celíaca em pacientes pediátricos e adultos com tireoidite autoimune e sua correlação com parâmetros clín icos. <https://repositorio.unb.br/handle/10482/34530>.

López, P. P., Ponguta, C. M. \& Gutiérrez, C. M. (2017). Prevalence of kidney involvement during the first year of follow-up in patients with HenochSchönlein purpura in a pediatric institution in Bogotá, Colombia. Revista Colombiana de Reumatología (English Edition), 24(2), 63-9.

$<$ https://www.elsevier.es/en-revista-revista-colombiana-reumatologia-english-edition--474-articulo-prevalence-kidney-involvement-during-firstS2444440517300481>.

Maldini, G. (2019). Conheça a tireoidite de Hashimoto, uma das principais causas do hipotireoidismo. Website da Faculdade de Medicina UFMG. Publicado: 03/10/2019 . <https://www.medicina.ufmg.br/conheca-a-tireoidite-de-hashimoto-disfuncao-silenciosa-da-tireoide/> .

Maruichi, M. D. et al. (2018). Características de crianças e adolescentes portadores de Diabetes Mellitus tipo 1 ao diagnóstico. Comparação entre dois períodos com dez anos de diferença em serviço universitário/Characteristics of children and adolescents with type 1 Diabetes Mellitus at diagnosis. Comparison of two periods ten years apart in a University Hospital. Arquivos Médicos dos Hospitais e da Faculdade de Ciências Médicas da Santa Casa de São Paulo, 57(2), 558. <http://arquivosmedicos.fcmsantacasasp.edu.br/index.php/AMSCSP/article/viewFile/281/293>.

Mendonca, A. E. A. et al. (2020). Aspectos sobre a etiopatogênese e terapêutica do vitiligo. Revista de Medicina, 99(3), 278-85.

<https://www.revistas.usp.br/revistadc/article/view/156202>.

Meneses, D. V. C. (2019). Investigação dos níveis de 25 (OH) D e suplementação de vitamina D3 em pacientes com vitiligo. $<$ https://ri.ufs.br/handle/riufs/13076>.

Michalek, I. M. et al. (2016). A systematic review of worldwide epidemiology of psoriasis. J Eur Acad Dermatol Venereol. 31 (2): $205-212$. doi: 10.1111 / jdv.13854. 2016. Disponível em: https://pubmed.ncbi.nlm.nih.gov/27573025/

Ministério da saúde (2019). Protocolo clínico e diretrizes terapêuticas diabete melito tipo 1.

<http://portalarquivos2.saude.gov.br/images/pdf/2019/novembro/18/Protocolo-Cl--nico-e-Diretrizes-Terap--uticas-do-Diabete-Melito-Tipo-1.18.11.2019.pdf〉.

Ministério da saúde (2019). Protocolo Clínico e Diretrizes Terapêuticas de Púrpura Trombocitopênica Idiopática.

<http://conitec.gov.br/images/Consultas/Relatorios/2019/Relatorio_PCDT_PTI_CP14_2019.pdf〉.

Mota, L. S. et al. (2020). Miopatia inflamatória idiopática. Desafios-Revista Interdisciplinar da Universidade Federal do Tocantins, 7(2), 137-45.

$<$ https://sistemas.uft.edu.br/periodicos/index.php/desafios/article/view/8853>.

Narciso, L. (2019). Manual Informativo para o doente com LUPUS. SPR. <https://www.lupus.pt/wp-content/uploads/2019/02/ManualLupus_SPR.pdf>. 
Okido, A. C. C. et al. (2017). As demandas de cuidado das crianças com Diabetes Mellitus tipo 1. Escola Anna Nery Revista de Enfermagem, 21 (2), 1-7. <https://www.scielo.br/scielo.php?pid=S1414-81452017000200206\&script=sci_arttext $>$.

Oliveira, E. A. et al. (2018). Influência do Diabetes Tipo 1 na análise simbólica e complexidade da variablidade da frequência cardíaca em jovens adultos. Arq Bras Cardiol, 111(1), 94-101. <scielo.br/scielo.php?pid=S0066-782X2018005009102\&script=sci_abstract\&tlng=pt>.,

Oliveira, M. C. L. A. et al. (2006). Clinical course of autoimmune hemolytic anemia: an observational study. Jornal de Pediatria, [s.1.], 82(1), 58-62. <http://www.rbac.org.br/wp-content/uploads/2019/12/RBAC-vol-51-3-2019-revista-completa.pdf>.

Oliveira, V. S. et al. (2019). Achados laringoscópicos em pacientes com artrite reumatóide em um serviço de referência em otorrinolaringologia da região norte. <http://repositorioinstitucional.uea.edu.br/handle/riuea/1258>.

Orge, M. S. G. et al. (2017). Efeitos dos exercícios fisioterapêuticos nas miopatias inflamatórias idiopáticas: uma revisão sistemática. Revista Baiana de Saúde Pública, [s.1.], 41(1), 236-53. Secretaria da Saude do Estado da Bahia. <https://www.scielo.br/scielo.php?pid=S1414$81452017000200206 \&$ script=sci_arttext $>$

Peixoto, A. et al. (2011). Febre reumática: revisão sistemática. Rev Soc Bras Clin Med, 9(3), 234-8. <http://files.bvs.br/upload/S/16791010/2011/v9n3/a1983.pdf>

Picon, P. D. et al. (2013). Protocolos clínicos e diretrizes terapêuticas. https://www.lume.ufrgs.br/bitstream/handle/10183/133105/000972622.pdf?sequence=1

Provan, D. \& Newland, A. C. (2015). Current management of primary immune thrombocytopenia. Advances in therapy, $32(10), 875-87$. <https://www.ncbi.nlm.nih.gov/pmc/articles/PMC4635183/>.

Queiroz, A. M. et al. (2017). Elaboração e caracterização de cookies sem glúten enriquecidos com farinha de coco: uma alternativa para celíacos. Brazilian Journal of Food Technology, 20. <https://www.scielo.br/scielo.php?pid=S1981-67232017000100423\&script=sci_abstract\&tlng=pt>.

Rebelo, M. S. R. (2019). Líquen plano e esqemas terapêuticos: estudo epidemiológico no Centro Hospitalar Lisboa Norte (HSM) referente ao período 20082017. Tese de Doutorado. <https://repositorio.ul.pt/handle/10451/41489>.

Reis Neto, E., Torres D. O. S. \& Pollak, D. F. (2008). Miopatias inflamatórias no idoso. Einstein, São Paulo, 6(1), $48-54$.

<https://www.academia.edu/39087030/Tratado_de_Neurologia_da_Academia_Brasileira_de_Neurologia>.

Rezende, M. U., Campos, G. C. \& Pailo, A. F. (2013). Conceitos atuais em osteoartrite. Acta Ortopédica Brasileira, 21(2), 120-22.

Ribeiro, B. E. V. G. G. (2019). A utilização do laser no tratamento do líquen plano oral. <https://repositorio.ul.pt/handle/10451/41489>.

Ribeiro, T. A. G. J. et al. (2018). Epidemiologia da esclerose múltipla na cidade de Goiânia no ano de 2015. http://repositorio.bc.ufg.br/tede/handle/tede/9111

Rocha, S., Gandolfi, L., Santos, J. E. (2016). Os impactos psicossociais gerados pelo diagnóstico e tratamento da doença celíaca. Revista da Escola de Enfermagem da USP, 50(1), 66-72. <https://www.scielo.br/scielo.php?pid=S0080-62342016000100065\&script=sci_abstract\&tlng=pt>.,

Rodrigues, A. P. et al. (2019). Qualidade de vida em pacientes portadores de doenças reumáticas. Revista Brasileira de Educação em Saúde, Pombal, 9(1), 613. <?https://www.atenaeditora.com.br/wp-content/uploads/2019/06/E-BOOK-Ciencias-da-Saude-da-Teoria-a-Pratica-5-1.pdf> .

Rodrigues, F. M. et al. (2015). Apresentação atípica da oftalmopatia de Graves. Revista Brasileira de Oftamologia, 74(4). Rio de Janeiro. <https://www.scielo.br/scielo.php?script=sci_arttext\&pid=S0034-72802015000400244>.

Sampaio-Barros, P. D. et al. (2007). Consenso brasileiro de espondiloartropatias: espondilite anquilosante e artrite psoriásica diagnóstico e tratamento primeira revisão. Revista Brasileira de Reumatologia, São Paulo, 47(4), 233-42. <https://www.scielo.br/pdf/rbr/v47n4/a01v47n4.pdf>.

Sampaio-Barros, P. D. et al. (2007). Recomendações sobre diagnóstico e tratamento da espondilite anquilosante. Revista Brasileira de Reumatologia, 53(3), 242-57. <https://www.scielo.br/scielo.php?script=sci_arttext\&pid=S0482-50042013000300003>.

Selleski, N. et al. (2018). Prevalence of celiac disease predisposing genotypes, including HLA-DQ2. 2 variant, in Brazilian children. Arquivos de gastroenterologia, 55(1), 82-5. <https://www.scielo.br/scielo.php?pid=S0004-28032018000100082\&script=sci_abstract>.

Setores da Endocrinologia (2015). Protocolo de hipotireoidismo (no adulto). HU.UFSC. <http://www.hu.ufsc.br/setores/endocrinologia/wpcontent/uploads/sites/23/2015/01/PROTOCOLO-DE-HIPOTIREOIDISMO-2-NO-ADULTO-OK-20-de-julho.pdf>.

Silva, A. C. S. et al. (2013). Lúpus: efeitos nos cuidados de si e nas relações familiares. Psicologia em Revista, 19(1), 30-42.

http://pepsic.bvsalud.org/scielo.php?script=sci_abstract\&pid=S1677-11682013000100004

Silva, D. R. A. (2017). Doenças autoimunes e manifestações na cavidade oral. Tese de Doutorado. <https://bdigital.ufp.pt/bitstream/10284/6485/1/PPG_27416.pdf>.

Silva, G. D. et al. (2018), Perfil de gastos com o tratamento da Artrite Reumatoide para pacientes do Sistema Único de Saúde em Minas Gerais, Brasil, de 2008 a 2013. Ciência \& Saúde Coletiva, 23(1), 1241-53. <https://www.scielo.br/scielo.php?pid=S1413-81232018000401241\&script=sci_abstract\&tlng=pt>.

Ministério da saúde (2011). Doenças reumáticas atingem 12 milhões de brasileiros. <http://www.brasil.gov.br/noticias/saude/2011/10/doencas-reumaticasatingem-12-milhoes-de-brasileiros>.

Sociedade Brasileira de Dermatologia (2020). Psoríase o que é? Website da Sociedade Bras. Dermatologia. <https://www.sbd.org.br/dermatologia/pele/doencas-e-problemas/psoriase/18/>. 
Research, Society and Development, v. 10, n. 2, e50410212681, 2021

(CC BY 4.0) | ISSN 2525-3409 | DOI: http://dx.doi.org/10.33448/rsd-v10i2.12681

Sontag, I. et al. (2017). Estado de humor na Artrite Reumatoide. ConScientiae Saúde, 16(3), 327-34. 〈https://www.redalyc.org/pdf/929/92953906003.pdf>.

Souza, G. R. et al. (2015). Febre Reumática e Streptococcus pyogenes-uma relação perigosa. Revista Científica Augustus, p. 1-7.

〈https://www.arca.fiocruz.br/bitstream/icict/30221/2/lucio_ribeiro_ioc_mest_2018.pdf〉.

Sztajnbok, F. R. et al. (2001). Doenças reumáticas na adolescência. J Pediatr, 77(2), 234-44. <http://www.jped.com.br/conteudo/01-77-s234/port.pdf>.

Tolentino Jr., D. S. (2017). Estudo da prevalência de doenças autoimunes na microrregião de saúde de Águas Formosas-Minas Gerais-Brasil. <http://acervo.ufvjm.edu.br/jspui/bitstream/1/1636/1/dilceu_silveira_tolentino_junior.pdf >.

Vieira, R. M., Nascimento, F. B. P. B. Jr \& et al. (2018). Espectro do envolvimento do sistema nervoso central em doenças reumáticas: ensaio pictórico. Radiologia Brasileira, $\mathrm{N}^{\circ}$ ahead. <https://www.finersistemas.com/atenaeditora/index.php/admin/api/artigoPDF/15217>.

Vieira, A. R. M. et al. (2018). Um novo conceito para o tratamento de esclerose múltipla. Revista Brasileira de Ciências da Vida. 6(Especial).

Wibelinger, L. M. (2019). Fisioterapia em reumatologia. Thieme Revinter Publicações LTDA,

<https://www.finersistemas.com/atenaeditora/index.php/admin/api/artigoPDF/15217〉. 